Increasing Interest in Computer Science through Group Work: A Goal Congruity Approach

by

Amanda Kay Montoya, Allison Master, Sapna Cheryan

Senior Thesis, Psychology Honors Program (2013)

University of Washington 


\begin{abstract}
Women's underrepresentation in science, technology, engineering, and math (STEM) fields is well established; however, there is much variation in women's among STEM fields. Women received $60 \%$ of bachelor's degrees in biology but only $18 \%$ of computer science degrees in 2009. One explanation for this difference may be social stereotypes of the fields. Male-dominated STEM fields are stereotyped as asocial, which may lead women to think that these fields will not give them opportunities to work with and help others. Three studies examined how communal goals, goals related to creating and maintaining interpersonal relationships, relate to interest in STEM fields. Study $1(N=120)$ found that women were more likely than men to endorse communal goals. Additionally, women were more interested in STEM classes they thought would fulfill their communal goals. Participants' communal goal endorsement was negatively correlated with their interest in male-dominated STEM fields, like computer science. Study $2(N=296)$ examined group work as a potential factor that could affect perceptions of communal fulfillment in science classes. Classes with group work were perceived to be higher in communal goal fulfillment. Male-dominated STEM fields were perceived to have less group work than female-dominated STEM fields. Additionally, preference for group work was positively correlated with communal goals. Study $3(N=91)$ experimentally manipulated the collaboration policy of a computer science class syllabus, testing for changes in communal goal fulfillment and interest. The class with a pro-collaboration policy was perceived as having the most communal goal fulfillment, but these perceptions did not carry over to perceptions of the field of computer science as a whole. These studies suggest that increasing opportunities for communal experiences in computer science may help women to feel that computer science would fulfill their goals, increasing their interest in the field.
\end{abstract}


Increasing Interest in Computer Science through Group Work: A Goal Congruity Approach

Women's representation in some science, technology, engineering, and mathematics (STEM) fields remains low, even though in the past 30 years many advances have been made in their representation in other traditionally male-dominated fields. Computer science is often identified as one of the most male-dominated STEM fields, with only $18 \%$ of bachelors' degrees in computer science awarded to women in 2009, compared to other fields that have attained gender parity like biology and chemistry, 60\% and 50\% respectively (NSF, 2009). Why are there still so few women in some STEM fields but not others?

Gender differences in goals could potentially explain gender disparities in different fields, because student's life goals often play a major role when choosing a major and future career (Eskilson \& Wiley, 1998; Morgan, Isaac, \& Sansone, 2001). Women tend to endorse communal goals, those goals that aim towards creating and maintaining interpersonal interactions, more than men (Diekman, Clark, Johnston, Brown, \& Steinberg, 2011; Pohlmann, 2001). Morgan, Isaac, and Sansone (2001) found that not only do men and women differ in their goals (with women preferring interpersonal goals) but that STEM fields are perceived to fulfill interpersonal goals less than social science, medical, and educational fields. Just as perceptions of goal fulfillment vary across broad fields, such as medicine compared to STEM, could these differences in perceptions of life goal fulfillment be used to predict why women are less interested in some STEM fields like computer science, but still remain interested in other STEM fields like biology?

In Studies 1 through 3, I examine how students' goals and perceptions of how much their goals would be fulfilled by different STEM fields predict interest in those fields. Study 1 establishes that there are differences between STEM fields in perceptions of goal fulfillment (e.g., biology is found to fulfill communal goals more than computer science). Study 2 examines how group work may contribute to these differences in perception: classes with group work are perceived as more communal, and biology classes are expected to have more group work than computer science classes. Finally, Study 3 experimentally manipulates group work in a computer science class, to examine whether the inclusion of group work can increase perceptions of communal goal fulfillment, therefore increasing women's interest in computer science. 
Perceptions of academic fields are often influenced by stereotypes; specifically in the case of computer science, those stereotypes can communicate that the field contradicts the societal expectations of women to be socially adept and helpful (Cejka \& Eagly, 1999; Diekman, Brown, Johnston, \& Clark, 2010). This contradiction may also include communal goals; that is, stereotypes of computer science may influence women to think that computer science would not fulfill their goals of helping others. Role congruity theory suggests that women tend to choose activities, like majors or classes, which align with their gender role. This preference is driven by personal goals that aim towards gender appropriate behavior (Diekman \& Eagly, 2008). These gender appropriate goals, communal goals, drive women to choose majors and classes that will fulfill those goals, which do not include computer science.

\section{Women and Computer Science}

The underrepresentation of women in computer science has been the focus of interdisciplinary research since the early 1990s (Dryburgh, 2000). The field of computer science overall has been growing as reflected in the awarded bachelor's degrees in recent decades: from 1981 to 2009, awarded bachelor's degrees in computer science increased by more than $250 \%$, whereas total bachelor's degrees have only risen about $60 \%$ in the same time period (U.S. Department of Education, 2010). Though the field itself is growing, a meta-analysis of women and computing showed that women's representation in computer science has been declining (Singh, Allen, Scheckler \& Darlington, 2007). From 1981 to 2009, the percentage of bachelor's degrees in computer science awarded to women declined from $33 \%$ to $18 \%$ (NSF, 2009). This phenomenon is not limited to college students: only $21 \%$ of students who took the AP Computer Science test in 2011 were female (College Board, 2011).

This gender disparity results in many missed opportunities for both women and the field of computer science. Even though women use computers as much as men (Singh et al., 2007), women are not well represented by the creators of the products they are using. Computer science provides products for a variety of users, and in order for the needs of the target population to be met, members of that population need to have input in the creation process. For instance, in 2011 a series of mainstream media articles highlighted a number of voice recognition devices that could not recognize women's voices (McMillan, 2011; Silke Carty, 2011), and research on voice recognition technology that is meant to assist with dictations in the medical field has revealed 
less accuracy for female voices (Science Daily, 2007). It is important to give a female voice to products that will inevitably be used by women.

Women are also missing out on the opportunity to participate in a very lucrative and successful field (Margolis \& Fisher, 2002). As such, an increase in female participation in computer science would benefit women in particular, but also society as a whole through female innovations in the field. In order to reap the benefits of female innovation, we need to find ways to get more women to participate in the field. Increasing women's interest would likely increase their participation, and some research has been successful in finding ways to increase women's interest.

\section{Increasing Interest}

Research that has successfully increased women's interest in computer science has done so by identifying stereotypes of computer science, and working to counteract those stereotypes by providing an alternate view of the field. In one series of studies done in person and in virtual environments, students were shown two computer science classrooms: one classroom was decorated stereotypically, with gaming memorabilia and computer parts, while the other classroom was decorated non-stereotypically, with nature posters and plants. Participants were asked to choose which they would prefer, to rate their interest and belonging in each classroom, and to rate the masculinity of each class (Cheryan, Meltzoff, \& Kim, 2011; see also Cheryan, Plaut, Davies, \& Steele, 2009). Female non-CS majors rated the stereotypical class higher in masculinity and were less interested in it; the perceived masculinity of each classroom negatively predicted women's interest in computer science. By identifying the masculine stereotype of computer science, and allowing female participants to choose between a classroom that was contradictory to their gender identity and one that was more aligned with their identity, Cheryan and colleagues (2011) showed that female participants preferred more gender congruent computer environments. The gender congruency of a field can be perceived in many ways other than the decoration of classrooms, including peers and potential role models.

Research examining the masculine stereotype of peers in computer science has found that women prefer female role models, and less stereotypical role models. After an interaction with a potential peer or expert role model, women showed more interest in computer science if role models, both experts and peers, were female (Dasgupta, 2011). Other research on peers tested the 
impact of a stereotypical role model on students after an interaction (Cheryan, Siy, Vichayapai, Drury, \& Kim, 2011). The stereotypical role models embodied hobbies, interests, and clothing that college students felt would be stereotypical of someone interested in computer science (e.g., a t-shirt saying "I code therefore I am"). This research found that when female college students interacted with a stereotypical peer they showed lower interest in computer science regardless of the peer's gender, compared to an interaction with a non-stereotypical peer. Central to both of these experiments was a manipulation that exposed participants to an individual who confirmed or counteracted their stereotypes, and by providing an alternative to the masculine perception of computer science, increased women's interest in computer science.

\section{Belonging and Interest}

Stereotypes of a field may drive several factors that influence interest and career choices, including "ambient belonging," the feeling that you belong in your environment, and perceived similarity, the feeling that you are similar to other people in the field. Role congruity theory posits women and men act in ways that align with the socially expected behaviors of their gender (Diekman \& Eagly, 2008). This essentially maximizes ambient belonging by reducing others' negative judgments based on any gender incongruent characteristics. Additionally, acting in a gender congruent manner increases perceived similarity to others of the same gender. By choosing fields that are congruent with societal expectations, women choose jobs that optimize their sense of belonging. Because computer science has been identified as incongruent with the female gender role (Diekman et al., 2011), it follows that women would not feel like they belong in the field. Research examining actual female college students in an intensive computer science program showed that women were highly concerned with their feelings of dissimilarity to their peers in the same courses, and $20 \%$ of women questioned whether they belonged in the field based on these differences (Margolis \& Fisher, 2002). Margolis and Fisher's research shows that women are less interested in computer science when they feel like they do not belong; however, research shown to increase belonging by eliminating gender incongruent cues concurrently increases interest (Cheryan, Meltzoff, \& Kim, 2011). Therefore, in order to identify more factors that could increase women's belonging in computer science, it may be useful to first identify some stereotypes of computer science, such as masculinity (Cheryan, Meltzoff, \& Kim, 2011), that could potentially decrease the belonging of women in the field. 


\section{Computer Science Stereotypes: Asocial Solitude}

Current stereotypes of computer scientists reflect that they are often asocial and tend to work in solitude, and many studies have reflected this perception of a lack of sociability in STEM students (Bair \& Marcus, 2007; Barman, 1999; Margolis \& Fisher, 2000; Mercier, Baron, \& O’Connor, 2004; Schott \& Selwyn, 2000). For example, in one study, college students rated other students who often used computers as being very low in sociability (Schott \& Selwyn, 2000). However, in the same study, the students who used computers often rated themselves at the same level of sociability that other students did. This difference between self-perception and perception of others reflects a stereotypic view that computer users are not social, even though they may actually be as social as the other students. Bair and Marcus (2007) noted that IT professionals were more likely to agree that programming is not for loners compared to women who were not majoring in IT. Again, there seems to be a stark disparity in perceptions of sociability of computer scientists, reflecting an asocial stereotype of the field held by those outside the field.

Not only are computer scientists stereotyped as asocial, but this stereotype extends into the perceptions of the work place of computer scientists: that they do not work together. One method of examining the stereotypes held about different types of people and jobs is a drawing test. In these tests participants, usually children, are told to draw the subject of study, and the drawings are analyzed by counting common characteristics of the drawings. Results of "draw a scientist" and "draw a computer scientist" tests often show male scientists working alone, instead of with others (Barman, 1999; Mercier, Baron, \& O’Connor, 2004). Similarly, a common theme noted throughout interviews of adolescent girls about their interests in computer science was that they would "rather work with people than computers," reflecting a perception that computer scientists tend to work with computers instead of interacting with other people (Rommes, Overbeek, Scholte, Engels, \& De Kemp, 2007). This common misconception, the dichotomy of technology and sociability, continues on into the later years of college computer science education. Margolis and Fisher's (2002) investigation of the perceptions of female college students at Carnegie Mellon reflected a common perception that the men in the field often worked alone. In addition, the women in computer science were interested in connecting their work to other fields that were more people-oriented, but they felt that their male peers did not 
share this interest. Because stereotypes of computer science reflect an asocial, work-alone environment, women are deterred from entering the field because they believe it will not fulfill their communal goals.

\section{Women and Communalism}

Communalism, the tendency to work with others and help others, is a factor previously identified as highly congruent with the female gender role (Diekman \& Eagly, 2008). A metaanalysis of prosocial behaviors found that women participated in certain prosocial behaviors more than men, specifically, communal prosocial behaviors and prosocial behaviors specific to helping individuals rather than groups (Eagly, 2009). In addition, Morgan, Isaac, and Sansone (2001) found that women more highly endorsed interpersonal goals (e.g., helping others), and those goals predicted interest in different STEM majors. Even in women's use of computers, research has shown that women tend to care more about the social uses of computers, whereas men tend to focus on the machine (Brunner \& Bennett, 1997; Margolis, Fisher, \& Miller, 1999). Women's goals reflect societal expectations of women's communal activities, and these expectations are reflected in the expected skills required for different jobs. One study showed that participants rated female personality traits, including a desire to help others and work with others, as the most important factor for being skilled in female-dominated fields (Cejka \& Eagly, 1999). Thus, communalism is expected in female-dominated fields; however, it is not expected in computer science, as it is a male-dominated field. So how does the perception of communalism in work fields influence women's interest?

\section{Communalism and Work Interest}

Because women are more interested in goals like communalism than men, it makes sense that perceived communal goals in a work field positively predict women's interest in that field. Indeed, in a study where female participants rated their interest in a number of fields (including both STEM and non-STEM), how communal they felt the fields were, and how important communal goals were to them, they found that women were least interested in low communal fields (STEM fields) and that the importance of communal goals mediated this effect for men and for women (Diekman, Eagly, \& Johnston, 2010). Similar research found that women became less interested in a non-communal field (computer science) when reminded of their 
communal goals (Diekman et al., 2011). In that study, female participants completed a priming activity that either put them in a communal or neutral mindset. Female participants who were primed to be in a communal mindset were significantly less interested in pursuing computer science. These results reflect how the stereotype of computer science is incongruent with female students' goals. Working with others and helping others are communal priorities reflected in women's choice of jobs; however, the stereotype of computer science does not match their goals, and reminding women of their goals increases this effect.

\section{Computer Science: Perception versus Experience}

Based on previous research, I expect that computer science, a female minority field, will be perceived as a low communal field, but how accurate is this stereotype of computer science? Even though the stereotype of computer science is not communal, the professionals in the field express a need for communal activities in their everyday work. A study asking practicing computer scientists how much they work with others in a day showed that on average $37 \%$ of each work day was spent working with at least one other person (Williams, 2006). Additionally, in a study comparing IT professionals to non-IT majoring college students, the IT professionals strongly endorsed the idea that programming is helpful to the community, and agreed that IT professions are not for those people "seeking isolation" (Bair \& Marcus, 2007). So even though computer scientists spend a good portion of their time working with others and believe that computer science fulfills communal goals, like working with others and helping the community, why are there still perceptions that computer scientists are not communal?

The educational structure of computer science may act as a cue, confirming students' stereotype that computer science is not communal. In early computer science classes, group projects are practically nonexistent, but in junior and senior level classes group projects are the focus of the classes (Margolis \& Fisher, 2002). Similarly, introductory computer science classes often have very few applications to show students how this field may be of assistance to other fields; however, in the later years of study, classes are more likely to focus on the applications of computer science (Margolis, Fisher, \& Miller, 1999). Margolis and colleagues (1999) argue that this type of class design potentially deters women from continuing on in computer science. By reinforcing the stereotype of computer science as non-communal, introductory classes may be deterring women from taking the class in the first place, or continuing on after taking the class. 
This research examines a potential underlying factor that may explain this phenomenon, expectations of communal goal fulfillment.

In summary, women's disinterest, and subsequent underrepresentation in computer science, can be explained by their feelings of belonging in the field. Previous research has identified stereotypes of computer science that deter women, and has successfully increased interest by providing alternate views of the fields, and thereby increasing feelings of belonging in the field (Cheryan, Meltzoff, \& Kim, 2011; Cheryan, Siy, et al., 2011; Dasgupta, 2011). One stereotype of computer science found consistently throughout the literature is that computer scientists are asocial and work alone (Barman, 1999; Margolis \& Fisher, 2002; Mercier, Baron, \& O’Connor, 2004; Schott \& Selwyn, 2000). Women tend to enjoy working with others and being social, so these computer science stereotypes and the preferences of women contradict each other, explaining some of women's disinterest in computer science. Studying this effect in computer science is important, because previous research examining the structure of computer science education in universities has shown that even though communal goal fulfillment is present in later classes, it is less prevalent in introductory classes. This lack of communal goal fulfillment in introductory classes could be a potential factor that drives women away from studying computer science. My research examines this effect by comparing communal goal fulfillment in different STEM classes and their relationship to interest in taking a class in that field.

\section{The Current Research}

This research differs from previous research on interest in computer science in terms of the context within which computer science is examined, and proposed explanations of differences in perceptions of communal goal fulfillment. Many research studies have examined interest in just computer science (e.g., Cheryan, Meltzoff, \& Kim, 2011; Cheryan et al., 2009), while other research has examined STEM in general (e.g., Murphy, Steele \& Gross, 2007), and some research compares STEM fields to fields outside of STEM like English (e.g., Diekman et al., 2010). In contrast, this research examines computer science interest inside the context of other STEM fields. This context is beneficial because reasons for interest can be variable in comparing fields like English to computer science, but comparing among STEM fields can 
provide a more precise understanding for why certain STEM fields appeal more to women, specifically perceptions of how much the fields assist in achieving communal goals. I aim to gain an understanding of how some STEM fields have progressed in gaining gender parity, while those like computer science continue to be highly male dominated.

I begin by broadly surveying interest and perceptions of a variety of STEM fields, and examining the relationships between personal goals, perceptions of goal fulfillment across fields, and interest and belonging (Study 1). Next I examine how group work is connected to views of communalism in different STEM fields, and how it may act as a cue to students, signaling communal fulfillment (Study 2). I continue by manipulating group work in a computer science class to examine if there is a causal relationship between group work and perceptions of communal fulfillment and ultimately interest (Study 3). Finally, I discuss the contribution of this research to current literature on women's interest in computer science, and how these results could impact future curricular choices for schools in the design of their computer science programs.

\section{Study 1}

Study 1 explores the interest of men and women in six different STEM fields, which span a variety of gender representations. Participants rate their interest, belonging, and how likely each class would be to fulfill communal goals, as well as how important communal goals are to them personally, referred to as "personal communal endorsement." I have four primary hypotheses:

1) Female-dominated STEM fields will be rated higher in communal goal fulfillment than maledominated STEM fields.

2) Women will be most interested in female-dominated fields, and men will be most interested in male-dominated fields.

3) Women will rate communal goals as more important than men.

4) Personal communal goal endorsement will positively predict interest in female-dominated and negatively predict interest in male-dominated fields.

\section{Methods}


Participants. I collected responses from 120 participants (60 female) University of Washington students, approached on campus to take part in a voluntary study. The majority of the participants were White (45\%) and Asian or Asian American (34.2\%). Participants were from all years of study: $11.7 \%$ freshmen, $25.8 \%$ sophomores, $24.2 \%$ juniors, $20 \%$ seniors, $13.4 \%$ other (e.g., graduate students, postbacs), and 5\% unspecified. The most prevalent current or probable majors of participants were psychology (8.3\%) and biology (7.5\%).

Measures and procedure. Participants who were sitting alone on campus were approached on campus by a researcher, and asked to fill out a questionnaire. Participants were asked to imagine they were interested in taking an introductory science class. The science courses included biology, psychology, mathematics, physics, computer science, and engineering. Participants then answered identical measures examining interest, belonging, and perceived masculinity of each field. After assessing each field, participants rated the personal importance of four goals, and then rated how well each field would assist them in achieving each goal. Finally participants filled out demographic information (gender, ethnicity, year, major, etc.). The researcher returned when the participant had finished the questionnaire, and thanked the participant for his or her participation.

Academic fields. Fields were selected based on the percentage of female students in each major awarded bachelor's degrees between 2001-2009 (NSF, 2009). All fields were sorted by gender representation: female dominated $(>60 \%)$, gender equal $(40 \%>$ and $<60 \%)$ or male dominated $(>60 \%)$. I selected two fields that are female dominated: psychology (77.5\% female) and biological sciences (61.0\%), two fields that are gender equal: physical sciences (41.9\%) and mathematics and statistics (45.2\%), and two fields that are male dominated: computer sciences (77.3\%) and engineering (80.4\%). These three groups (female dominated, gender equal, and male dominated) will be referred to as the "gender representation groups."

Interest. Participants completed four items of measuring interest for each field (e.g., “How interested are you in taking a class in Biology?”). I adapted the measures from previous research on interest in taking a class in computer science (Cheryan et al., 2009). Participants rated each item on a 7-point Likert scale ranging from 1 (Not at all) to 7 (Extremely). I calculated an interest measure for each field by averaging responses to the following questions: a) "How interested are you in taking a class in [field]," b) "How much would you want to take a class in [field]," c) "How likely would you be to choose a class in [field]," and d) "How much have you 
considered majoring in [field]" (for scale reliability, see Table 1). An overall interest measure for each gender representation group (female dominated, gender equal, and male dominated) was calculated by averaging the interest measures for each of the fields within the group. Interest in female-dominated classes was calculated by averaging interest in psychology and biology $(M=$ 3.90). Interest in gender-equal classes was calculated by averaging interest in mathematics and physics $(M=3.63)$. Interest in male-dominated classes was calculated by averaging interest in computer science and engineering $(M=3.44)$.

Belonging. I used four items to measure belonging for each field. I adapted the items from previous research on ambient belonging in computer science classes (Cheryan et al., 2009). Participants rated each item of belonging on a 7-point Likert scale ranging from 1 (Not at all) to 7 (Extremely). A belonging measure for each field was calculated by averaging responses to the following questions: a) "How much do you think you would fit in with the students in a [field] class," b) "How similar do you think you are to the students in a [field] class," c) "How much do you think you belong in a [field] class," and d) "How much do you think you would fit into the environment of this [field] class" (for reliability, see Table 1). I calculated an overall belonging measure for each gender representation group by averaging the belonging variables for each included field. Belonging in female-dominated classes was calculated by averaging belonging ratings in psychology and biology $(M=4.06)$. Belonging in gender-equal classes was calculated by averaging belonging in mathematics and physics $(M=3.82)$. Belonging in male-dominated classes was calculated by averaging belonging in computer science and engineering $(M=3.42)$.

Personal endorsement of communal goals. I measured personal endorsement of communal goals as a potential mediator of gender differences in interest in the fields included in each female representation group. Four items examined personal communal goal endorsement (e.g., "How important is helping others to you personally?"). Specific communal goals were selected from research on interest in occupational fields and communal goals (Diekman et al., 2011). Participants rated each item on a 7-point Likert scale ranging from 1(Not at all) to 7 (Extremely). I calculated participants' overall endorsement of communal goals by averaging across all four items of personal communal endorsement $(M=5.41, \alpha=.85)$.

Field goal fulfillment. Participants rated how much each field would assist in achievement of each of the communal goals (e.g., "Caring for others") on a scale from 1 (Not at all) to 7 (Extremely). I calculated an overall communal goal fulfillment variable for each field by 
averaging responses to the four communal goals (for scale reliabilities and means, see Table 1). Overall measures of communal fulfillment for each gender representation group were calculated by averaging the communal goal fulfillment measures for the fields within each gender representation factor.

\section{Results}

Hypothesis 1: Gender representation and perceived goal fulfillment. To investigate the first hypothesis, that female-dominated fields would be perceived as more communal, I performed a 3 (gender representation group: male dominated, gender equal, and female dominated $) \times 2$ (participant gender) mixed model ANOVA on perceived communal goal fulfillment. There was no significant main effect of gender, $F(2,222)=1.39, p=.29$. The three gender representation groups were significantly different, $F(2,222)=76.05, p<.001$. I conducted post-hoc t-tests to confirm directionality of communal perceptions between the groups. As expected, a one-tailed t-test showed that female-dominated fields were perceived as significantly more communal than male-dominated fields, $t(112)=6.80, p<.001$, and gender equal fields, $t(112)=10.99, p<.001$. Perceived communal fulfillment was higher in maledominated fields compared to gender equal fields, $t(112)=6.64, p<.001$.

Hypothesis 2: Gender differences in class interest. To investigate the second hypothesis, that gender and interest in classes would interact (i.e., women would be most interested in female-dominated fields and men would be most interested in male-dominated fields), I performed a 3 (gender representation group: male dominated, gender equal, and female dominated $\times 2$ (participant gender) mixed model ANOVA on interest. There was a marginally significant main effect of gender representation factor, $F(2,112)=2.98, p=.053$, where participants' interest differed between male-dominated fields $(M=3.44, S D=1.77)$, gender equal fields $(M=3.63, S D=1.54)$, and female-dominated fields $(M=3.90, S D=1.39)$. As predicted, there was a significant interaction between gender and gender representation factor, $F(2,112)=19.50, p<.001$ (see Figure 1).

To examine this effect with respect to gender, post-hoc comparisons showed that women were significantly more interested in female-dominated fields compared to male-dominated fields, $t(59)=5.11, p<.001$, and gender-equal fields, $t(59)=4.79, p<.001$. Women were also more interested in gender-equal fields compared to male-dominated fields, $t(59)=2.32, p<.05$. 
Men were significantly less interested in female-dominated fields compared to gender-equal fields, $t(58)=2.33, p<.05$, and marginally less interested in female-dominated fields compared to male-dominated fields, $t(59)=1.72, p=.09$. I found no significant difference in men's interest in male-dominated fields compared to gender equal fields, $t(57)=0.03, p=.98$.

Looking at the same interaction another way, I found that women were significantly more interested in female-dominated fields compared to men, $t(117)=2.53, p<.001$. Men were significantly more interested than women in both male-dominated fields, $t(117)=4.82, p<.001$, and gender equal fields, $t(116)=4.09, p<.001$.

Hypothesis 3: Gender differences in communal goal endorsement. To examine the third hypothesis that women endorse communal goals more than men, I computed a two tailed ttest on personal importance of communal goals. There was a significant different between male and female participants in communal goal endorsement, $t(116)=-2.08, p<.05$, where female participants endorsed communal goals $(M=5.63, S D=1.15)$ significantly more than male participants $(M=5.18, S D=1.17)$.

Hypothesis 4: Communal goal endorsement and class interest. To examine the fourth hypothesis, that communal goal endorsement will positively predict interest in female-dominated fields, and negatively predict interest in male-dominated fields, I conducted a series of correlations. Communal goal endorsement positively predicted interest in female-dominated fields, $r(118)=.34, p<.001$, and negatively predicted interest in male-dominated fields, $r(118)=$ $-.24, p<.01$.

\section{Discussion}

As hypothesized, female-dominated STEM fields were rated highest in communal goal fulfillment, and women's interest was highest in female-majority STEM fields. Also as predicted, women rated personal endorsement of communal goals higher than men, and personal endorsement of communal goals predicted interest in STEM fields: positively for femaledominated fields, and negatively for male-dominated fields.

Similar to previous research that showed male-stereotypic STEM fields were perceived to fulfill communal goals less than female-stereotypic (Diekman et al., 2011), this research replicates and extends this result with a fundamental difference: instead of comparing male- 
dominated STEM fields to female-dominated fields not in STEM, I compare male-dominated STEM fields to female-dominated STEM fields. I found that female-dominated fields are perceived to assist students the most in communal goals, compared to male-dominated STEM fields.

This research aims to understand what drives interest in academic fields. One possibility is that perception of gender representation within a field drives interest in a field: women are most interested in fields with women, and men are most interested in fields with men. Alternatively, the driving factor may not be the representation of one's own gender in the field, but rather the perception that the field will fulfill goals that are either congruent or incongruent with one's gender role. Study 1 showed that women are most interested in highly communal fields, which are congruent with their gender role, while men are least interested in highly communal fields. However, it remains unclear whether the difference in communal goal fulfillment is responsible for the difference in interest between the genders.

Studies 2 and 3 examine this question using group work as a characteristic of classes that acts as a communal cue. By examining whether group work acts as a communal cue (Study 2), then manipulating it in a field previously conceived as low in communal fulfillment, like computer science (Study 3), we can examine whether there is a causal relationship between group work and interest. Identifying a causal relationship between group work and interest would suggest that perceptions of goal fulfillment affect gender differences in interest.

\section{Study 2}

Previous research indicates that communal goals are positively related to interest in female-dominated careers, and negatively related to interest in male-dominated STEM fields (Diekman et al., 2010; Diekman et al., 2011). Study 1 replicated this effect in terms of academic classes. But why are female-dominated classes perceived to be more communal than maledominated classes? One potential difference between male-dominated and female-dominated classes that may explain this difference is that there may be cues in female-dominated classes that communicate that they fulfill communal goals, like opportunities for group work. Study 2 examined whether perceived communal fulfillment is different in classes with group work compared to classes with individual work, and whether preference for group work is related to personal endorsement of communal goals. 
Why would group work attract women to take a class? Group work may act as an observable cue to potential goal fulfillment. As in research by Cheryan, Meltzoff, and Kim (2011) where stereotypical environmental cues suggested to female participants that a computer science class was masculine, I expect that group work will cue participants to think that a class will fulfill communal goals. Diekman and Eagly (2008) posit that people choose to participate in activities, especially their occupations, that they believe will help fulfill their goals, and for women those are more likely to be communal goals. Because communal goals involve working with and helping others, group work may be seen as an opportunity to create communal interactions, cueing to women that this field will fulfill their communal goals.

Indeed, working in groups has been connected to successful interventions in improving recruitment of underrepresented groups, including women, to STEM fields (Triesman, 1992; Williams, 2006; Williams et al., 2003), suggesting that group work may be an effective direction for research on the recruitment of women into STEM.

Study 2 examines the connections between group work and communal goals in relation to college classes. I have three primary hypotheses:

1) Classes with group work will be perceived as more communal than classes where students work individually.

2) Female-dominated classes will be expected to have more group work than male-dominated classes.

3) Students' communal goals will be positively correlated with their preference for group work.

\section{Methods}

Participants. We collected responses from 296 participants (184 female, 109 male, and 3 unspecified) University of Washington students in an introductory psychology class. Participants took part in a voluntary questionnaire session where they responded to multiple questionnaires. The majority of the participants were Asian American (49.32\%) and White (35.47\%). Participants were mostly freshman (66.21\%) and sophomores (22.97\%). The average age of our participants was $18.84(S D=2.32)$. The most prevalent current or probable major of the participants were psychology (10.14\%), undecided (10.14\%), and biology (9.80\%).

Measures and procedure. Participants were administered the questionnaire in a set of six total questionnaires, completed in a single class session. The questionnaire asked participants 
questions measuring their personal preference for group work, the communal goal fulfillment of classes where students work individually, the communal goal fulfillment of classes where students work in groups, their perception of group work in computer science, biology, psychology, and engineering, and their personal communal goal endorsement. Finally participants filled out demographic information (gender, ethnicity, year, major, etc.).

Group work preference. Four items measured group work preference (e.g., "If given the choice, I would prefer to work as part of a group rather than work alone."). Three of these items were adapted from previous research on teamwork effectiveness, by replacing the word "team" with "group" in each item (Campion, Medsker, \& Higgs, 1993). The fourth item was developed to be similar to the other items in the scale but more directed toward classroom learning: "I would prefer a class with group work compared to one where we work individually." All items were rated on a 7-point Likert scale ranging from 1 (Strongly Disagree) to 7 (Strongly Agree). Group work preference was measured by averaging responses to the four items $(\alpha=.86)$.

Communal goal fulfillment of classes. I used ten items to measure communal goal fulfillment of classes (e.g., "Taking a class where we work in groups would assist me in serving the community.”). Five items examined classes "where we work individually" and five items examined classes "where we work in groups." For each type of class (group work or individual), I measured five communal goals (helping others, serving the community, working with others, connecting to others, and caring for others). Participants rated all items using 7-point Likert scale ranging from 1 (Strongly Disagree) to 7 (Strongly Agree). I calculated a communal goal fulfillment measure for group classes by averaging across communal goal fulfillment measures for classes with group work $(\alpha=.79)$, and the same process was taken to calculate a communal goal fulfillment measure for classes with individual work $(\alpha=.80)$.

Perceived group work in STEM. Four items measured perception of group work in STEM (e.g., "Taking a biology class would likely involve a lot of group work."). These items asked about biology, psychology, computer science, and engineering. These four fields were selected from Study 1 as the fields with the highest and lowest percentages of women receiving bachelor's degrees (NSF, 2009). Participants rated all items on a 7-point Likert scare ranging from 1 (Strongly Disagree) to 7 (Strongly Agree). I calculated a measure for perceived group work in female-dominated STEM classes by averaging across the items on biology $(M=4.58$, $S D=1.47)$ and psychology $(M=4.32, S D=1.34, \alpha=.37)$. I calculated a measure for perceived 
group work in male-dominated STEM classes by averaging across the items on computer science $(M=3.48, S D=1.43)$ and engineering $(M=4.37, S D=1.44, \alpha=.33)$.

Personal goal endorsement. I measured personal goal endorsement as a potential correlate of group work preference. Five items examined communal goal endorsement (e.g., "How important is helping others to you personally?"). Specific communal goals were selected from research on interest in occupational fields and communal goals (Diekman et al., 2011). Participants rated each of the items on a 7 point Likert scale ranging from 1 (Not at all) to 7 (Extremely). I calculated participants' overall communal goal endorsement by averaging across all five measures of communal goal endorsement $(\alpha=.81)$.

\section{Results}

\section{Hypothesis 1: Communal goal fulfillment in classes with group versus individual}

work. To examine the hypothesis that classes with group work would be perceived as more communal than those with individual work, I performed a paired samples t-test between communal fulfillment for classes with group work and classes where students work individually. As predicted, classes with group work $(M=5.33, S D=0.83)$ were rated significantly higher than classes where students worked individually $(M=3.23, S D=0.96)$ on communal goal fulfillment, $t(294)=26.19, p<.001$ (see Figure 2). This demonstrates that students perceive that classes with group work would be more likely to fulfill their communal goals compared to classes where students work individually.

Hypothesis 2: Group work in male-dominated versus female-dominated classes. To examine the second hypothesis that female-dominated science classes were expected to have more group work than male-dominated science classes, I performed a paired samples t-test between expected group work in female-dominated classes and male-dominated classes. As predicted, female-dominated science classes $(M=4.45, S D=1.02)$ were rated higher than maledominated science classes $(M=3.92, S D=1.11)$ on expected group work, $t(293)=6.99, p<$ .001 . This result shows that students expect that taking a female-dominated STEM class would allow more group work than taking a male-dominated STEM class.

\section{Hypothesis 3: The relationship between communal goals and preference for group}

work. Finally, to test the hypothesis that communal goals would be positively correlated with preferred group work, I correlated preference for group work $(M=4.07, S D=1.24)$ and personal 
communal goal endorsement $(M=5.59, S D=0.89)$. Preference for group work was significantly correlated to personal communal goal endorsement, $r(292)=.26, p<.001$.

\section{Discussion}

All three hypotheses were confirmed, replicating previous work that showed the connection between group work and communal goals. New findings from this research showed that male-dominated science fields were expected to have less group work than femaledominated fields, suggesting that students expect differences in amount of group work between the two types of classes. Because classes with group work were perceived to be more communal, previous research would suggest that women would be more interested in classes they perceive to include group work.

Overall, these results may suggest that differences between science classes are not just limited to their content, but also the perception of group work available in the class. This difference in perceptions could lead students to select their classes based on availability of group work, rather than class content. Future examination of whether students consider group work in their class selection process could explain gender divisions in different fields over and above the idea that men and women are just interested in different things.

These findings suggest that the addition of group work, or promotion of existing group work, in male-dominated science fields could potentially increase the perception of communal fulfillment in those fields. Adding group work could appeal to students who have a preference for group work and place a high value on communal goals. As seen in Study 1, women in particular may be more likely to value communal goals. Thus, this addition of group work may help women to feel that male-dominated STEM fields would fulfill their goals and could result in subsequent increased interest. Study 3 examines whether manipulating group work in a computer science syllabus creates greater interest among women.

\section{Study 3}

Can experimentally manipulating group work in an introductory computer science class affect students' interest in the class and the field of computer science? Previous research has found a causal relationship between perceptions of communal goal fulfillment and interest in working in the field of computer science (Diekman et al., 2011); however, such evidence has not 
been found in the academic environment. Study 3 manipulated collaboration policies as a representation of communal goal fulfillment in the syllabus of a computer science class, and we examined interest in computer science and perceptions of communal fulfillment.

Study 3 examines the causal relationship between collaboration and interest in computer science. I have three primary hypotheses:

1) A computer science class with a pro-collaboration policy will be perceived as more communal than a class with a no collaboration policy.

2) There will be a significant interaction between gender and condition, such that women will be more interested in the pro-collaboration class and less interested in the no collaboration class, whereas men will be more interested in the no collaboration class and less interested in the procollaboration class.

\section{Methods}

Participants. We collected responses from 130 participants; however, 36 participants were eliminated for having taken the class that the syllabus was about and three participants were eliminated for failing the manipulation check. Participants included in the analyses were 91 (60.4\% female, $38.5 \%$ male, and $1.1 \%$ unspecified) University of Washington students approached on campus to take part in a voluntary study. The majority of the participants were White (40.7\%) and Asian/Asian American (39.6\%). Participants were mostly freshman (35.2\%) and juniors $(26.4 \%)$. The average age of participants was $20.51(S D=2.88)$. The most prevalent current or probable majors of the participants were psychology (8.8\%) and biology (6.6\%).

Measures and procedure. Participants who were sitting alone on campus were approached on campus by a researcher and asked to fill out a questionnaire. Participants were asked to imagine they were interested in taking an introductory science class, then read a syllabus for an introductory computer science class. Each participant read one of three syllabi. One syllabus encouraged students to work with their fellow students (pro-collaboration), another syllabus said students were not allowed to work with their fellow students (no collaboration), and the third syllabus made no statements about whether or not students could work with their fellow students (control; See Appendix for exact syllabi). Participants then answered identical measures examining interest, retention, and perceived masculinity. Then participants assessed the perceived communal goal fulfillment of the class they read about, and of the field of computer 
science. Participants then rated their preference for group work, and personal goal endorsement. Finally participants filled out demographic information (gender, ethnicity, year, major, etc.). The researcher returned when the participant had finished the questionnaire, and thanked the participant for his or her participation.

Interest. Participants completed three items measuring interest adapted from the items used in Study 1. Participants rated each item on a 7-point Likert scale ranging from 1 (Not at all) to 7 (Extremely). I calculated an overall interest measure by averaging responses to the following questions: a) "How interested are you in taking the class you read about," b) "How much would you want to take the class you read about," and c) "How likely would you be to choose the class you read about," $(\alpha=.94)$. An additional forced choice measure was included: "Would you choose to take this class?" Participants could respond "Yes" or "No" to this question.

Retention. Previous research by McDowell, Werner, Bullock, and Fernald (2003) suggested that retention is higher in classes with collaboration compared to classes without. Participants answered two questions concerning their retention in the field of computer science: "How much have you considered majoring in computer science?" and "If you chose this class, how likely would you be to take another class in this department?" These measures were averaged to calculate a retention measure $(\alpha=.67)$.

Masculinity. Cheryan, Meltzoff, and Kim (2011) suggested that more masculine classroom environments would deter women. As potential covariates, two questions measured perceived masculinity of the class. Participants responded to the first question, "How masculine or feminine do you rate the students in the class you read about?" on a scale ranging from 1 (Very Masculine) to 7 (Very Feminine). Participants also responded an open ended item, "What percentage of people in the class you read about do you think are women?"

Communal goal fulfillment of classes and field. Participants completed the five items from Study 1 measuring communal goal fulfillment of the class (e.g. "Taking this class would assist me in helping others."). The same five items were altered to measure communal goal fulfillment of the computer science field (e.g., "Computer Science would assist me in working with others."). I measured five communal goals: helping others, serving the community, working with others, connecting to others, and caring for others. Participants rated all items using a 7point Likert scale ranging from 1 (Strongly Disagree) to 7 (Strongly Agree). I calculated a communal goal fulfillment measure for the class by averaging across communal goal fulfillment 
measures for the class $(\alpha=.83)$, and the same process was taken to calculate a communal goal fulfillment measure for the field of computer science $(\alpha=.88)$.

Group work preference. The same four items from Study 2 measured group work preference (e.g., "If given the choice, I would prefer to work as part of a group rather than work alone.”). All items were rated on a 7-point Likert scale ranging from 1 (Strongly Disagree) to 7 (Strongly Agree). Group work preference was measured by averaging responses to the four items $(\alpha=.89)$.

Personal goal endorsement. The same five items from Studies 1 and 2 examined communal goal endorsement (e.g., "How important is helping others to you personally?"). Participants rated each of the items on a 7 point Likert scale ranging from 1(Not at all) to 7 (Extremely). I calculated participants' overall communal goal endorsement by averaging across all five measures of communal goal endorsement $(\alpha=.86)$.

\section{Results}

Hypothesis 1: Group work and perceived goal fulfillment. To investigate the first hypothesis, that pro-collaboration classes would be perceived as more communal, I performed a 3 (condition: pro-collaboration, no collaboration, or control) $\times 2$ (participant gender) ANOVA on perceived communal fulfillment of the class. There was no significant effect of participant gender, $F(1,84)=0.10, p=.75$, and there was no significant interaction between participant gender and condition, $F(2,84)=1.20, p=.30$. There was a significant main effect of condition, $F(2,84)=4.18, p=.019$. Pairwise comparisons showed that the pro-collaboration class $(M=$ $3.86, S D=1.06)$ was perceived as more communal than the no collaboration class $(M=2.93, S D$ $=1.36, p=.005)$, and not significantly different from the control $(M=3.49, S D=1.23, p=.33)$. The control condition was perceived as marginally more communal compared to the nocollaboration class $(p=.093)$. Though there was no interaction with condition, the behavior of the control condition is important to the interpretation of results. Pairwise comparisons showed that for men the control condition $(M=3.73, S D=.54)$ was significantly different from the nocollaboration condition $(M=2.66, S D=1.23, p=.04)$, but not significantly different from the pro-collaboration condition $(M=3.77, S D=1.13, p=.93)$. Women showed a different effect, where the control condition $(M=3.26, S D=1.47)$ was marginally different from the procollaboration condition $(M=3.94, S D=1.03, p=.08)$, but not significantly different from the 
no-collaboration condition $(M=3.20, S D=1.45, p=.89)$. This suggests that men may have expected the class to include collaboration, while women may have expected the class to not include collaboration.

In addition to the first hypothesis, I examined whether the manipulation would be strong enough to change overall perceptions of computer science. I performed a 3 (condition: procollaboration, no collaboration, or control) $\times 2$ (participant gender) ANOVA on perceived communal fulfillment of the field of computer science. I found no significant effect of gender, $F(1,84)=0.55, p=.60$, no significant effect of condition, $F(2,84)=0.38, p=.68$, and no significant interaction, $F(2,84)=0.37, p=.69$.

Hypothesis 2: Gender differences in class interest and retention. To investigate the second hypothesis, that gender and interest in classes would interact (i.e., women would be most interested in the pro-collaboration class and men would be most interested in the no collaboration class), I performed a 3 (condition: pro-collaboration, no collaboration, or control) $\times 2$ (participant gender) ANOVA on overall. There was a significant effect of gender, $F(1,84)=7.24, p=.009$, showing that men $(M=3.41, S D=1.44)$ were more interested overall compared to women $(M=$ $2.59, S D=1.41)$. There was no significant effect of condition, $F(2,84)=1.13, p=.33$. Additionally, there was a marginal interaction between gender and condition, $F(2,84)=2.37, p=$ .10. Men were less interested in the no-collaboration class $(M=2.61, S D=1.71)$ compared to the pro-collaboration class $(M=3.85, S D=1.21, p=.034)$ and marginally less interested compared to the control $(M=3.79, S D=1.14, p=.05)$, but women's interest did not vary based on class, $F(2,84)=0.21, \mathrm{p}=.81$. (See Figure 3 .)

To examine if this effect generalized to retention, I performed a 3 (condition: procollaboration, no collaboration, or control) $\times 2$ (participant gender) ANOVA on average retention. There were no significant effects of condition, $F(2,84)=1.14, p=.32$, gender, $F=$ $(1,84)=1.59, p=.21$, or interaction, $F(2,84)=1.66, p=.20$.

Analyses of masculinity. To examine if there were effects on perceived masculinity of the class I conducted a 3 (condition: pro-collaboration, no collaboration, or control) $\times 2$ (participant gender) ANOVA on perceived masculinity. There were no significant effects of gender, $F(1,83)=0.17, p=.68$, or interaction, $F(2,83)=.11, p=.89$. There was a marginally significant effect of condition, $F(2,83)=0.11, p=.06$. Pairwise comparisons showed that the nocollaboration class $(M=3.36, S D=0.89)$ was not significantly different from the pro- 
collaboration class $(M=3.17, S D=0.87, p=.44)$, and significantly more masculine than the control $(M=2.77, S D=2.77, p=.022)$. The pro-collaboration class did not significantly differ from the control with respect to masculinity $(p=.010)$.

To examine if there was an effect of condition or gender on expected percentage of women in the class, I conducted a 3 (condition: pro-collaboration, no collaboration, or control) $\times$ 2 (participant gender) ANOVA on expected percentage of women. There were no significant effects of gender, $F(1,79)=0.03, p=.87$, or interaction, $F(2,79)=1.05, p=.36$. There was a marginal effect of condition, $F(2,79)=2.47, p=.09$. Pairwise comparisons showed that the nocollaboration class $(M=34.66, S D=13.46)$ was perceived as having more women compared to the control $(M=26.45, S D=12.97, p=.03)$, and not significantly different from the procollaboration policy class $(M=29.98, S D=12.41, p=.19)$. The pro-collaboration class did not significantly differ from the control class $(p=.31)$.

\section{Discussion}

Neither of the hypotheses was confirmed, suggesting that adding collaboration to the syllabus did not effectively change women's interest in taking a computer science course. I found that manipulation of a collaboration policy was not, in this case, an effective cue for changing women's perceptions of communal goal fulfillment in the field of computer science, and that if anything our manipulation increased men's interest in taking a computer science class and had little effect on women.

The results of this study suggest that our manipulation was strong enough to influence perceptions of communal goal endorsement within the class, but not strong enough to influence perceptions of the whole field of computer science. Thus, it may be necessary to change perceptions of the field, not just a class, to influence women's interest in computer science. Future successful manipulations may have to be stronger in their presentation of communal goals, such as having assigned group work in the class or a focus on communal applications of computer science. Previous successful manipulations have offered a variety of examples of communal interactions in the workplace, in order to influence women's interest (Diekman et al., 2011). Perhaps a similar manipulation where students read about a computer science major's day involving many communal interactions would be a stronger manipulation of communal goal fulfillment in computer science. 
Based on our findings, men were more interested in the control and pro-collaboration class compared to the no collaboration class. This finding may be related either to goal fulfillment or some other variable affected by group work; for example, the class with group work may have seemed easier or less strict. Future research should examine men's reactions to collaboration policies to further explain these findings.

Another potential explanation of the increase in men's interest comes from the behavior of the control condition in Study 3. With respect to the communal goal fulfillment of the class, the pattern of participants' interest in the control condition differed depending on gender. Men's interest in the control condition did not differ from the pro-collaboration condition; whereas, women's interest in the control condition did not differ from the no-collaboration condition. This suggests that there may be different expectations of men and women when considering the communal goal fulfillment of computer science. Because Study 1 found no gender difference in expectations of communal goal fulfillment, but Study 3 found a gender difference in the control condition for expectations of communal goal fulfillment, future studies should replicate these findings. Specifically future studies should aim to answer the questions: Do men and women expect group work in computer science, or does the addition of group work alter expectations and potentially influence interest?

Future studies should examine stronger manipulations of communal goal fulfillment, while still maintaining consideration of practical changes that could be made in the education system. These may include changing syllabi to include assigned group projects, communal applications of computer science, or some combination of the two. Alternatively, there may be some moderator of interest and communal goal fulfillment that could explain our findings. Perhaps there may be other factors like stereotype threat that keep women from being interested in classes with group work, and if those concerns were alleviated, we may see more of an effect when manipulating group work.

Though this research did not find a causal relationship between collaboration policy and women's interest, previous research has successfully done so (Diekman et al., 2011) and I believe that many factors could explain differences in effects compared to the results of Diekman and colleagues. First, my manipulation was very small, and it may have been that participants did not pay enough attention to the syllabus as they read to digest the information. Additionally, because the manipulation was only of the collaboration policy, it did not directly manipulate 
group work, which was the manipulated variable in Study 2. Further, previous research has suggested that stereotype threat, the fear of confirming a negative stereotype about one's group, is an important factor for women's interest in STEM careers (Murphy, Steele, \& Gross, 2007; Shapiro \& Williams, 2012). It may be that stereotype threat could play a role in group work, because women would have to work closely with other students who they do not feel similar to, and they perceive may judge them based on their gender. Future studies should take measures of stereotype threat, to examine if adding group work also increases stereotype threat.

\section{General Discussion}

Women's goals play an important role in determining their interest in a field such as computer science. This finding may be key to understanding how to more effectively recruit women into fields where they are underrepresented. Across three studies, I found that the lack of perceived potential to fulfill communal goals in computer science was related to women's disinterest in computer science. In Study 1, women were most interested in classes with the highest communal goal fulfillment, and rated male-dominated classes, like computer science, as low in communal goal endorsement. Because women endorsed communal goals more than men, and communal goal endorsement was negatively correlated with interest in male-dominated fields, this relationship could explain gender difference in participation in computer science. In Study 2, I examined whether including group work in a class would increase perceptions of communal goal fulfillment, potentially leading to a solution to women's perception that computer science does not fulfill communal goals. I found that classes with group work were perceived to be more communal than classes without, and that expectations of group work were lower in male-dominated fields, like engineering and computer science, compared to femaledominated fields. In Study 3, I experimentally manipulated collaboration in a class through the class syllabus. I found that men were more interested in the pro-collaboration class and the control compared to the no-collaboration class. Women were largely unaffected by the manipulation.

\section{Computer Science: The Communal Disconnect}

Misperceptions of computer science may be deterring women away from computer science. Fields like computer science, which are perceived as more communal by those in the 
field compared to those outside the field (Bair \& Marcus, 2007), are untapped resources for helping women find jobs that fulfill their goals. Expressing to young women the true potential for communal interactions within computer science could help women rely less on their stereotypes, and potentially increase their interest in this field.

Similar to the differences previously found between IT professionals and college students, our findings suggest that the men and women of our sample have differing perceptions of computer science. Men perceive computer science to be more communal than women perceive it to be. This may be a potential explanation for gender differences in interest in computer science, and by investigating how these differences arise we may find the key to helping women develop accurate perceptions of STEM fields. Interviews by Margolis and Fisher (2002) suggested that male students often have more role models and experiences with computers early in life; these role models may help boys to gain a better understanding of computer science as a communal field.

As Studies 1 and 2 suggested, there are differences in perceptions of female-dominated fields and male-dominated fields with respect to communal goal fulfillment and group work. Additionally, Study 2 suggested that group work may influence perceptions of communal goal fulfillment. Previous research of group work in computer science has shown that it increases retention and results in better performance in later classes (Williams, 2006), and higher retention in the major (McDowell et al., 2003). Because group work could act as a potential cue for communal endorsement and also provide a positive computing experience, I believe it may be key for teaching women earlier that computer science is a communal field.

\section{Future Directions}

Addressing communal goals may be key to understanding previous findings regarding women's interest in computer science. Recent findings suggested that those with high math and verbal abilities, a group that is primarily female, choose STEM fields less often than those who have equally high math ability but lower verbal ability, a group that is primarily male (Wang, Eccles, \& Kenny, 2013). The authors suggest that this may be because the high math, high verbal individuals have a wider range of choices when choosing an occupation. But what leads them to choose fields outside of STEM compared to those inside? Perceptions of communal goal fulfillment could influence the interest of these individuals, and future research should examine 
if communal goals play a particularly large role in occupational choices for those who are gifted in both math and verbal skills.

Previous research on classroom environments has suggested that masculine environments (e.g. World of Warcraft posters, computer parts, and Spock bobble head) deter women from taking a computer science class by decreasing their feelings of belonging (Cheryan, Meltzoff, et al., 2011). Could classroom environments also communicate communal goal fulfillment and therefore increase women's interest in taking a class? For example, environments that contain seats arranged in groups may indicate greater communal goal fulfillment compared to environments that contain separated seating. It may be that being included in a group is important for women to feel like they belong in computer science, and classroom seating arrangement can help women to feel as if they are part of a group. Future studies should examine if including communal classroom decorations and seating arrangements would be influential on women's interest in taking a computer science class.

The focus of this research has been on appealing to women's interest in working with others; however, communal goals embody not only working with others, but also helping others. Previous research by Diekman and colleagues (2011) provided a manipulation of communal goals involving not only working with others but also helping others, and it may be the combination of the two that is required in order to appeal for women's goals. This may explain why women's interest was relatively unaffected by the manipulation in Study 3. Understanding which side of communal goals is most important or if a combination of the two is required to appeals to women's communal goals, would help further the research on the topic and assist in creating the most effective interventions aimed at helping women join the STEM fields.

While differences of perceptions between STEM and non-STEM fields have been studied previously (Diekman et al., 2010, Diekman et al., 2011), the current work focused on the differences of perceptions within STEM fields. Taking a STEM perspective allows us to filter out much of the variability in interest that could be explained by other factors, such as an overall disinterest in science. By comparing computer science to biology instead of English, this research has eliminated much of the variation in interest and can focus more closely on the role the perceptions of communal goal fulfillment play in influencing interest. Future research could narrow the perspective even more by focusing only on computer oriented fields, and by doing this could fully understand what drives people to be interested in one computer oriented field but 
not another. A report by the Computing Research Association (2012) found marked differences in women's participation in different computer oriented fields, specifically higher participation in informatics, compared to computer science and computer engineering. Investigating the differences in perceptions of computing fields like informatics and HCDE (human centered design and engineering) compared to computer science and computer engineering could inform psychology research in understanding how technical careers can be portrayed in more communal ways. Differences in rates of female participation in these fields could be driven by differences in perceptions of communal goal fulfillment.

\section{Conclusion}

As previously mentioned, the current design for computer science education may deter women from joining or continuing in computer science, by reinforcing the stereotype that computer science is not communal, even though advanced classes encourage communal goals by promoting applications to other fields as well as working in groups. The current research suggests that women tend to choose classes that promote the achievement of communal goals. Indeed, research by McDowell and colleagues (2003) found that women who took their introductory science course as a "paired programming" class (in which students work in pairs) were more likely to finish college with a computer science related major, compared to students who worked independently in their introductory class. Future research should continue to examine how manipulating the perception of communal goals in an introductory computer science class could affect women's interest in taking that class. Creating a more communal environment earlier in STEM education could be critical to recruiting and retaining women in the male-dominated fields. Increasing women's participation in computer science will increase women's participation in the innovation of products they use every day, and provide an opportunity to participate in a very lucrative and successful field (Margolis \& Fisher, 2002). Helping women feel welcome in a high paying and culturally important field like computer science would not only help women, but could potentially influence the quality of innovation coming from computer science to the everyday user. 


\section{References}

Bair, B., \& Marcus, M. (2007). Women's interest in information technology: The fun factor. In C. J. Burger, E. G. Creamer, \& P. S. Meszaros (Eds.), Reconfiguring the Firewall: Recruiting women to information technology across cultures and continents (pp. 161 175). Wellesley, MA: A. K. Peters Ltd.

Barman, C. J. (1999). Students' views about scientists and school science: Engaging K-8 teachers in a national study. Journal of Science Teacher Education, 10(1), 43-54. doi: 10.1023/ A:1009424713416

Brunner, C., \& Bennett, D. (1997). Technology and gender: Differences in masculine and feminine views. NASSP Bulletin, 81(46), 46-51. doi: 10.1177/019263659708159208

Campion, M. A., Medsker, G. J., \& Higgs, A. C. (1993). Relations between work group characteristics and effectiveness. Personnel Psychology, 46(4), 823-850.

Cejka, M. A., \& Eagly, A. H. (1999). Gender-stereotypic images of occupations correspond to the sex segregation of employment. Personality and Social Psychology Bulletin, 25(4), 413-423. doi: 10.1177/0146167299025004002

Cheryan, S., Meltzoff, A. N., \& Kim, S. (2011). Classrooms matter: The design of virtual classrooms influences gender disparities in computer science classes. Computers \& Education, 57(2), 1825-1835. doi:10.1016/j.compedu.2011.02.004

Cheryan, S., Plaut, V. C., Davies, P. G., \& Steele, C. M. (2009). Ambient belonging: how stereotypical cues impact gender participation in computer science. Journal of Personality and Social Psychology, 97(6), 1045-1060. doi: 10.1037/a0016239

Cheryan, S., Siy, J. O., Vichayapai, M., Drury, B. J., \& Kim, S. (2011). Do female and male role models who embody STEM stereotypes hinder women's anticipated success in STEM? Social Psychology and Personality Science, 2(6), 656-664. doi: 10.1177/ 1948550611405218

The College Board. (2011). Program Summary Report. AP Program participation and performance statistics. Retrieved from: http://professionals.collegeboard.com/datareports-research/ap/data

Dasgupta, N. (2011). Ingroup experts and peers as social vaccines who inoculate the selfconcept: The stereotype inoculation model. Psychological Inquiry, 22(4), 231-246. doi: 10.1080/1047840X.2011.607313 
Diekman, A. B., Brown, E. R., Johnston, A. M., \& Clark, E. K. (2010). Seeking role congruity between goals and roles: A new look at why women opt out of science, technology, engineering, and mathematics careers. Psychological Science, 21(8), 1051-1057. doi: $10.1177 / 0956797610377342$

Diekman, A. B., Clark, E. K., Johnston, A. M., Brown, E. R., \& Steinberg, M. (2011). Malleability in communal goals and beliefs influences attraction to STEM careers: Evidence for a goal congruity perspective. Journal of Personality and Social Psychology, 101(5), 902-918. doi: 10.1037/a0025199

Diekman, A. B., \& Eagly, A. H. (2008). Of men, women, and motivation: A role congruity account. In J. Y. Shah \& W. L. Gardner (Eds.), Handbook of motivation science (pp. 434447). New York, NY: Guilford Press.

Dryburgh, H. (2000). Underrepresentation of girls and women in computer science: Classification of 1990s research. Journal of Educational Computing Research, 23, 181202.

Eagly, A. H. (2009). The his and hers of prosocial behavior: An examination of the social psychology of gender. American Psychologist, 64(8), 644-658. doi: 10.1037/0003066X.64.8.644.

Eskilson, A., \& Wiley, M. G. (1998). Solving for the X: Aspirations and expectations of college students. Journal of Youth and Adolescence, 28(1), 51-70. doi: 10.1023/ A:1021620508097

Margolis, J., \& Fisher, A. (2000). The anatomy of interest: Women in undergraduate computer science. Women's studies quarterly, 28(1/2), 104-127.

Margolis, J., \& Fisher, A. (2002). Unlocking the clubhouse: Women in computing. Cambridge, MA: MIT Press.

Margolis, J., Fisher, A., \& Miller, F. (1999). Caring about connections: Gender and computing. IEEE Technology and Society Magazine, 18(4), 13-20. doi: 10.1109/44.808844

McDowell, C., Werner, L., Bullock, H. E., \& Fernald, J. (2003). The impact of pair programming on student performance, perception and persistence. Proceedings of the $25^{\text {th }}$ Internation Conference on Software Engineering, 602-607. 
McMillan, G. (2011). It's not you, it's it: Voice recognition doesn't recognize women. Time. Retrieved from http://techland.time.com/2011/06/01/its-not-you-its-it-voice-recognitiondoesnt-recognize-women/

Mercier, E. M., Barron, B., \& O’Connor, K. M. (2006). Images of self and others as computer users: The role of gender and experience. Journal of Computer Assisted Learning, 22, 335-348. doi: 10.1111/j.1365-2729.2006.00182.x

Morgan, C., Isaac, J. D., \& Sansone, C. (2001). The role of interest in understanding the career choices of female and male college students. Sex Roles, 44(5-6), 295 - 320.

Murphy, M. C., Steele, C. M., \& Gross, J. J. (2007). Signaling threat: How situational cues affect women in math, science, and engineering settings. Psychological Science, (18)10, 879 885.

National Science Foundation. (2009). TABLE 5-1. Bachelor's degrees, by sex and field: 19912009. Women, Minorities, and Persons with Disabilities in Science and Engineering. Division of Science Resource Statistics. Retrieved from http://www.nsf.gov/statistics/ wmpd/tables.cfm.

Pöhlmann, K. (2001). Agency- and communion-orientation in life goals: Impacts on goal pursuit strategies and psychological well-being. In P. Schmuck \& K. M. Sheldon (Eds.), Life goals and well-being: Towards a positive psychology of human striving (pp. 68-84). Seattle, WA: Hogrefe \& Huber.

Rommes, E., Overbeek, G., Scholte, R., Engels, R., \& De Kemp, R. (2007): I'm not interested in computers: Gender-based occupational choices of adolescents. Information, Communication \& Society, 10(3), 299-319.

Science Daily. (2007). Voice recognition systems seem to make more errors with women's dictation. Science Daily. Retrieved from http://www.sciencedaily.com/releases/2007/05/ $070504133050 . \mathrm{htm}$

Schott, G., \& Selwyn, N. (2000). Examining the “male, antisocial”" stereotype of high computer users. Journal of Educational Computing Research, 23, 291-303. doi: 10.2190/V98R5ETX-W9LY-WD3J

Silke Carty, S. (2011). Many cars tone deaf to women's voices: female voices pose a bigger challenge for voice activated technology than men's voices. AOL Autos. Retrieved from http://autos.aol.com/article/women-voice-command-systems/ 
Singh, K., Allen, K. R., Scheckler, R., \& Darlington, L. (2007). Women in computer-related majors: A critical synthesis of research and theory from 1994 to 2005. Review of Educational Research, 77(4). 500-533. doi: 10.3102/0034654307309919

Treisman, U. (1992). Studying students studying calculus: A look at the lives of minority mathematics students in college. The College Mathematics Journal, 23(5), 362 - 372.

U.S. Department of Education. (2010). Table 282. Bachelor's degrees conferred by degreegranting institutions, by field of study: Selected years, 1970-71 through 2008-09. Digest of Educational Statistics 2010. National Center for Education Statistics. Retrieved from http://nces.ed.gov/programs/digest/d10/

Williams, L., McDowell, C., Nagappan, N., Fernald, J., \& Werner, L. (2003). Empirical Software Engineering, 2003. pp. 143-152, doi:10.1109/ISESE.2003.1237973

Williams, L. (2006). Debunking the nerd stereotype with pair programming. Computer, 39(5), 83-85. doi: 10.1109/MC.2006.160

Zweben, S. (2012). Computing degrees and enrollment trends: From the 2010-2011 CRA taulbee survey. Computing Research Association. 


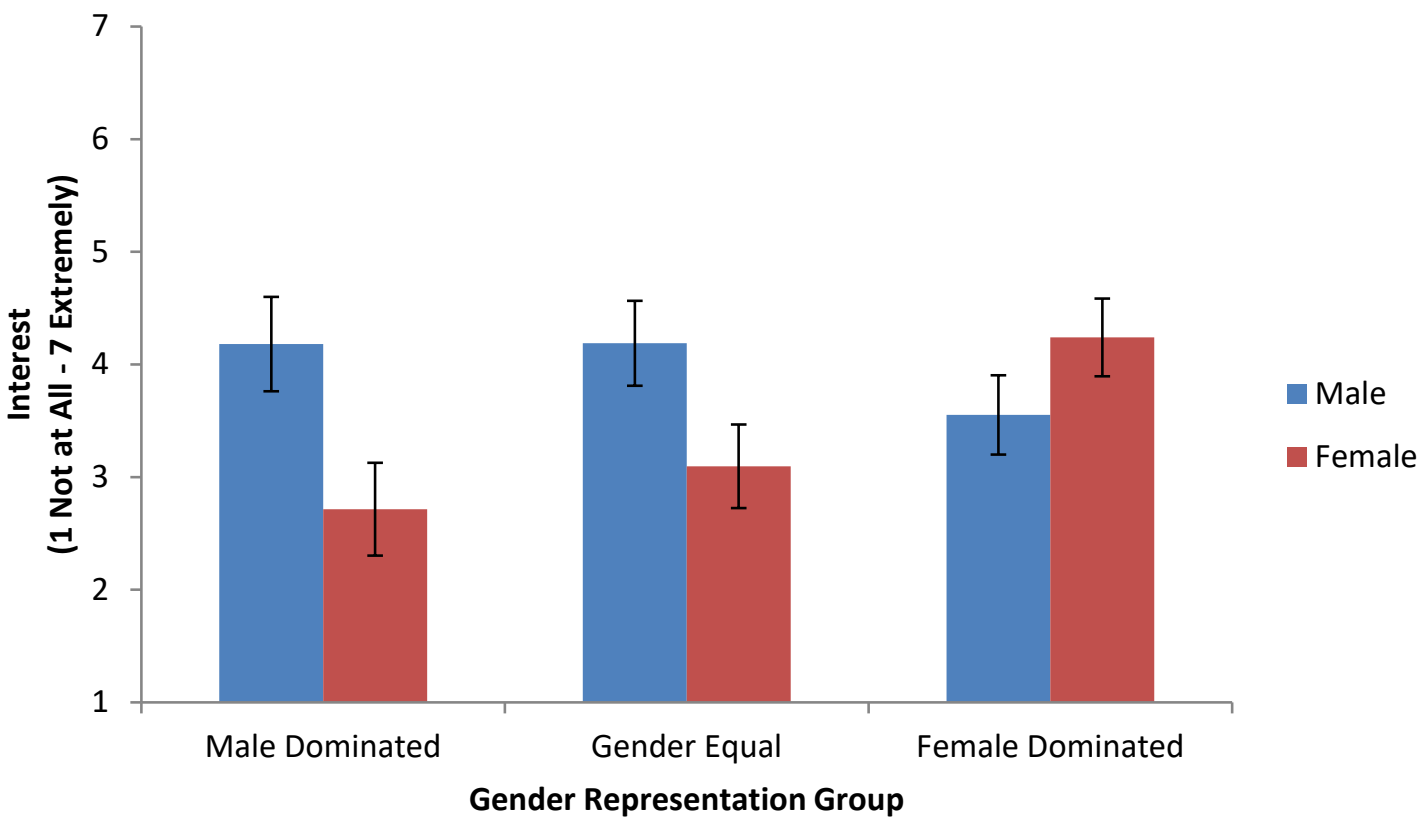

Figure 1: Study 1 Results. Men and women's interest in STEM fields by gender representation group. Error bars represent $95 \%$ confidence intervals. 


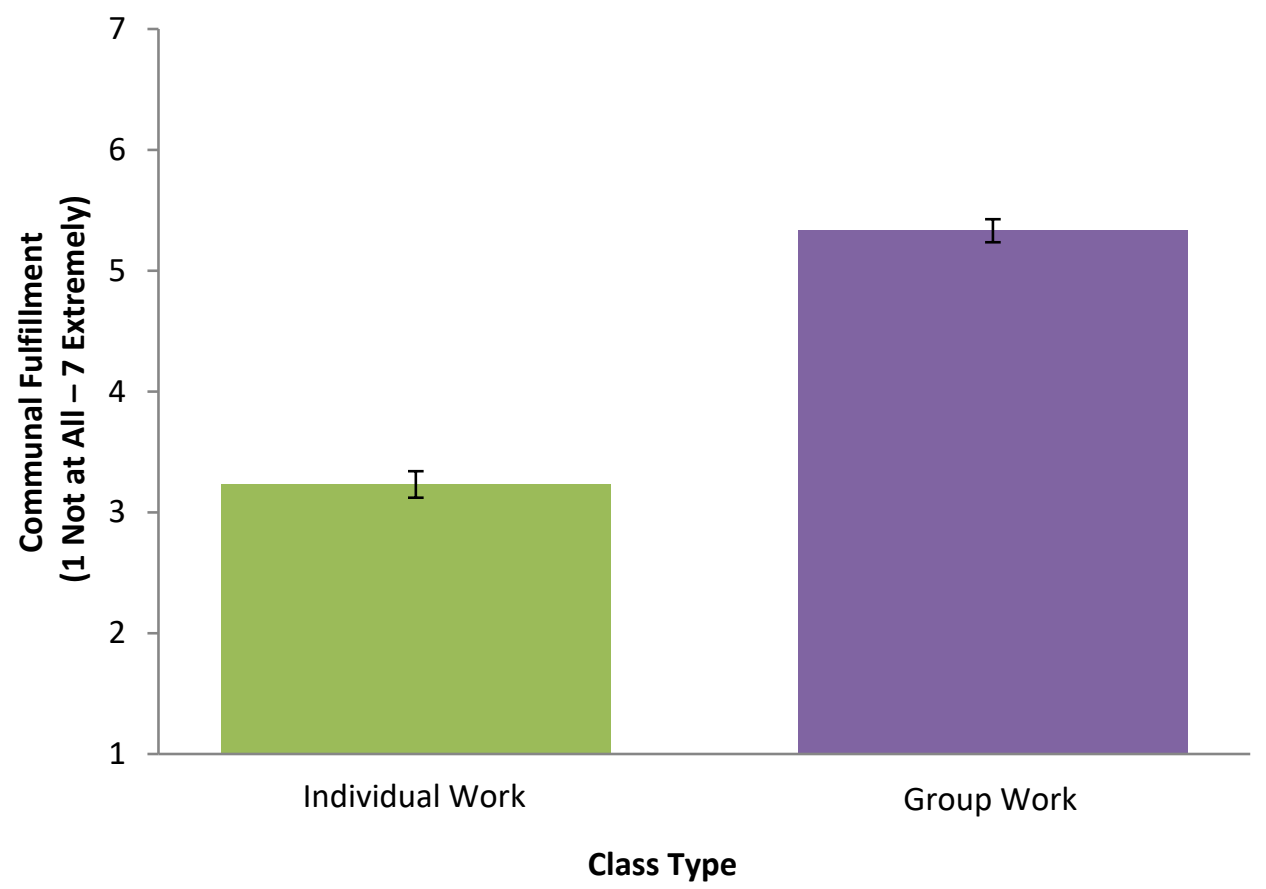

Figure 2: Study 2 Results. Classes with group work were perceived to be more communal than classes with individual work. Error bars represent 95\% confidence intervals. 


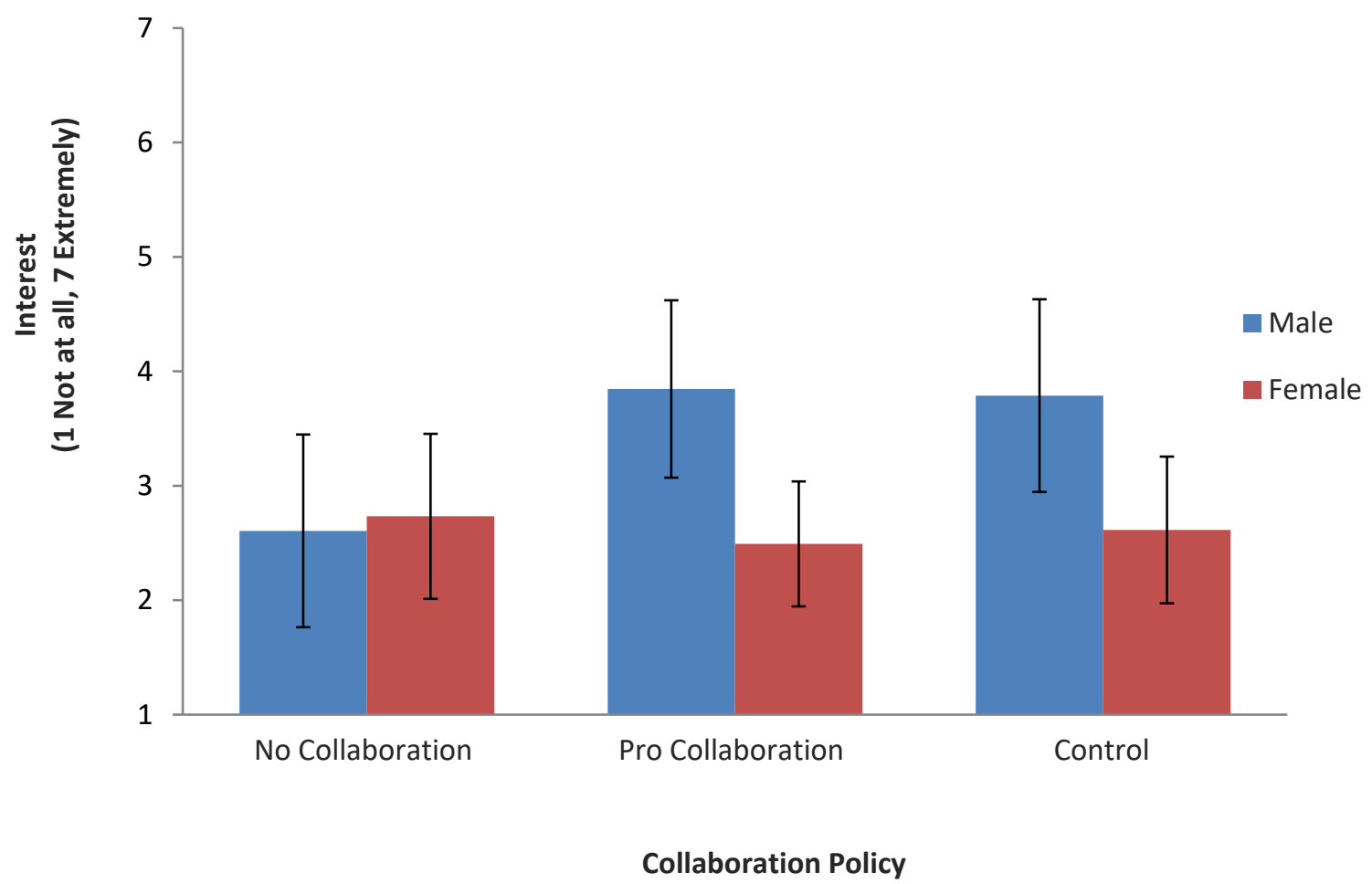

Figure 3: Study 3 results. Men were more interested in pro-collaboration and control conditions compared to no collaboration. Women showed no difference between conditions. Error bars represent $95 \%$ confidence intervals. 
Tables

\begin{tabular}{|c|c|c|c|}
\hline \multicolumn{2}{|c|}{ Table 1: Cronbach's $\alpha$ for Combined Variables } & \multirow[b]{2}{*}{ Mean } & \multirow[b]{2}{*}{ SD } \\
\hline Variable & $\alpha$ & & \\
\hline Female Dominated Interest & .87 & 3.90 & 1.38 \\
\hline Biology Interest & .93 & 3.55 & 1.74 \\
\hline Psychology Interest & .95 & 4.30 & 1.76 \\
\hline Gender Equal Interest & .91 & 3.63 & 1.54 \\
\hline Math Interest & .93 & 3.87 & 1.79 \\
\hline Physics Interest & .95 & 3.39 & 1.82 \\
\hline Male Dominated Interest & .95 & 3.42 & 1.76 \\
\hline CS Interest & .95 & 3.32 & 1.81 \\
\hline Engineering Interest & .97 & 3.51 & 2.09 \\
\hline Female Dominated Belonging & .87 & 4.07 & 1.14 \\
\hline Biology Belonging & .92 & 3.83 & 1.40 \\
\hline Psychology Belonging & .96 & 4.35 & 1.50 \\
\hline Gender Equal Belonging & .94 & 3.82 & 1.36 \\
\hline Math Belonging & .95 & 4.16 & 1.56 \\
\hline Physics Belonging & .96 & 3.49 & 1.50 \\
\hline Male Dominated Belonging & .95 & 3.42 & 1.50 \\
\hline CS Belonging & .94 & 3.40 & 1.56 \\
\hline Engineering Belonging & .96 & 3.41 & 1.72 \\
\hline Personal Communal Goal Endorsement & .85 & 5.41 & 1.78 \\
\hline Female Dominated Communal Fulfillment & .87 & 4.97 & 1.17 \\
\hline Biology Comm. Fulfill & .88 & 4.46 & 1.54 \\
\hline Psychology Comm. Fulfill & .87 & 5.46 & 1.32 \\
\hline Gender Equal Communal Fulfillment & .92 & 3.22 & 1.22 \\
\hline Math Comm. Fulfill & .89 & 3.15 & 1.38 \\
\hline Physics Comm. Fulfill & .87 & 3.29 & 1.27 \\
\hline Male Dominated Communal Fulfillment & .92 & 3.95 & 1.76 \\
\hline CS Comm. Fulfill & .86 & 3.65 & 1.37 \\
\hline Engineering Comm. Fulfill & .90 & 4.25 & 1.58 \\
\hline
\end{tabular}




\section{Appendix}

\section{No Collaboration Policy University of Washington Computer Science \& Engineering 142: Introduction to Programming I Course Syllabus}

\author{
Instructor \\ name: John Johnson \\ email: j.johnson $(a$ uw.edu \\ office: $\quad$ CSE 800 \\ office phone: (206)555-1234 \\ office hours: see course website
}

\section{Course Overview}

This course provides an introduction to computer science using the Java programming language. CSE 142 is primarily a programming course that focuses on common computational problem solving techniques. No prior programming experience is assumed, although students should know the basics of using a computer (e.g., using a web browser and word processing program) and should be competent with math through Algebra 1. The information, concepts, and analytical thinking introduced in lecture provide a unifying framework for the topics covered in CSE 143.

\section{Lecture Time}

MWF 12:00 PM - 1:00 PM, Classroom TBA

\section{Discussion Sections}

You will be expected to participate in a weekly discussion section, held on Thursdays (see course website for details). The TA who runs your section will grade your homework assignments. In section, we will answer questions, go over common enrors in homework, and discuss sample problems in more detail than lecture.

\section{Course Web Site}

- https/www.cs.washington.edu/142/

\section{Textbook}

- Reges/Stepp, Building Java Programs: A Back to Basics Approach (2nd Edition).

\section{Grading}

The primary assessment for your success in this class is exams. There will be 2 midterms and 1 final, and together they make up $85 \%$ of your grade. The homework assignments are designed to prepare you for your exams. The exams are designed to assess your ability to utilize the concepts you've learned from your homework and in lecture in new contexts.

$5 \%$ participation

$10 \%$ weekly homework assignments

$25 \%$ midterm 1

$25 \%$ midterm 2

$35 \%$ final exam

\section{Exams}

Our exams are closed-book and closed-notes, although each student will be allowed to bring a single index card with hand-written notes (no larger than 5 " by 8 "). No electronic devices may be used, including calculators. Make-up exams will not be given except in case of a serious emergency.

\section{Homework}

Homework consists of weekly assignments done individually and submitted electronically on the course web site. Disputes about homework grading must be made within 2 weeks of receiving the grade. If you don't make an honest effort on the homework, your exam score will reflect it.

\section{Academic Integrity and Collaboration}

Computer Science is best leamed through interacting with the material to ensure that you thoroughly understand each concept. Homework assignments must be completed individually. You may not discuss general ideas of how to approach an assignment with other students or discuss specific details about what to write with other students. Any help you receive from or provide to classmates should be limited. You may seek help from University of Washington CSE 142 TAs and professors.

You must abide by the following rules:

- You may not work with another student on homework assignments.

- You may not show another student your solution to an assignment, nor look at his/her solution.

- You may not have anyone describe in detail how to solve an assignment or sit with you as you write it.

- You may not post online about your homework to ask others for help. 


\section{Pro Collaboration Policy \\ University of Washington \\ Computer Science \& Engineering 142: Introduction to Programming I Course Syllabus}

\author{
Instructor \\ name: John Johnson \\ email: $\quad$ j.johnson $a$ uw.edu \\ office: CSE 800 \\ office phone: (206)555-1234 \\ office hours: see course website

\section{Course Overview}

This course provides an introduction to computer science using the Java programming language. CSE 142 is primarily a programming course that focuses on common computational problem solving techniques. No prior programming experience is assumed, although students should know the basics of using a computer (e.g., using a web browser and word processing program) and should be competent with math through Algebra 1 . The information, concepts, and analytical thinking introduced in lecture provide a unifying framework for the topics covered in CSE 143.

\section{Lecture Time}

MWF 12:00 PM - 1:00 PM, Classroom TBA

\section{Discussion Sections}

You will be expected to participate in a weekly discussion section, held on Thursdays (see course website for details). The TA who runs your section will grade your homework assignments. In section, we will answer questions, go over common enrors in homework, and discuss sample problems in more detail than lecture.

\section{Course Web Site}

- http://www.cs.washington.edu/142/

\section{Textbook}

- Reges/Stepp, Building Java Programs: A Back to Basics Approach (2nd Edition).

\section{Grading}

The primary assessment for your success in this class is exams. There will be 2 midterms and 1 final, and together they make up $85 \%$ of your grade. The homework assignments are designed to prepare you for your exams. The exams are designed to assess your ability to utilize the concepts you've learned from your homework and in lecture in new contexts.

$5 \%$ participation

$10 \%$ weekly homework assignments

$25 \%$ midterm 1

$25 \%$ midterm 2

$35 \%$ final exam

\section{Exams}

Our exams are closed-book and closed-notes, although each student will be allowed to bring a single index card with hand-written notes (no larger than 5 " by 8 "). No electronic devices may be used, including calculators. Make-up exams will not be given except in case of a senious emergency.

\section{Homework}

Homework consists of weekly assignments done in optional groups and submitted electronically on the course web site. Disputes about homework grading must be made within 2 weeks of receiving the grade. If you don't make an honest effort on the homework, your exam score will reflect it.

\section{Academic Integrity and Collaboration}

Computer Science is best leamed through interacting with your fellow students to ensure that you thoroughly understand each concept. Homework assignments may be completed with other students. You are strongly encouraged to discuss general ideas of how to approach an assignment with other students, and may discuss specific details about what to write with other students. Any help you receive from or provide to classmates should be cited in your assignment. You may seek help from University of Washington CSE 142 TAs, professors, and classmates.

You must abide by the following rules:

- You are highly encouraged to work with another student on homework assignments.

- You may not show another student outside of your class your solution to an assignment, nor look at his/her solution.

- You may not have anyone outside of your class describe in detail how to solve an assignment or sit with you as you write it.

- You may not post online about your homework, other than on the class discussion board, to ask others for help. 
Control

\section{University of Washington \\ Computer Science \& Engineering 142: Introduction to Programming I Course Syllabus}

\author{
Instructor \\ name: John Johnson \\ email: j.johnson $a$ uw.edu \\ office: CSE 800 \\ office phone: (206)555-1234 \\ office hours: see course website
}

\section{Course Overview}

This course provides an introduction to computer science using the Java programming language. CSE 142 is primarily a programming course that focuses on common computational problem solving techniques. No prior programming experience is assumed, although students should know the basics of using a computer (e.g., using a web browser and word processing program) and should be competent with math through Algebra 1. The information, concepts, and analytical thinking introduced in lecture provide a unifying framework for the topics covered in CSE 143.

\section{Lecture Time}

MWF 12:00 PM - 1:00 PM, Classroom TBA

\section{Discussion Sections}

You will be expected to participate in a weekly discussion section, held on Thursdays (see course website for details). The TA who runs your section will grade your homework assignments. In section, we will answer questions, go over common errors in homework, and discuss sample problems in more detail than lecture.

Course Web Site

- http://www.cs.washington.edu/142/

Textbook

- Reges/Stepp, Building Java Programs: A Back to Basics Approach (2nd Edition).

\section{Grading}

The primary assessment for your success in this class is exams. There wi. be 2 midterms and 1 final, and together they make up $85 \%$ of your grade. The homework assignments are designed to prepare you for your exams. The exams are designed to assess your ability to utilize the concepts you've learned from your homework and in lecture in new contexts.

$5 \%$ participation

$10 \%$ weekly homework assignments

$25 \%$ midterm 1

$25 \%$ midterm 2

$35 \%$ final exam

\section{Exams}

Our exams are closed-book and closed-notes, although each student will be allowed to bring a single index card with hand-written notes (no large than 5 " by 8 "). No electronic devices may be used, including calculators. Make-up exams will not be given except in case of a senous emergency.

\section{Homework}

Homework consists of weekly assignments, done and submitted electronically on the course web site. Disputes about homework grading must be made within 2 weeks of receiving the grade. If you don't make an honest effort on the homework, your exam score will reflect it. 